\title{
Morfonatomia do caule de Cuphea glutinosa Cham. \& Schltdl. (Lythraceae)
}

\author{
Adriana Maria Zago, ${ }^{1}$ Melânia Palermo Manfron, ${ }^{2}$ Ademir Farias Morel, ${ }^{3}$ \\ Gilberto Dolejal Zanetti",2
}

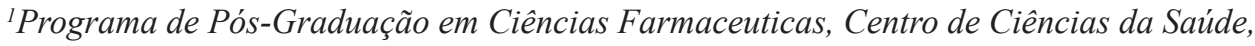 \\ Departamento de Farmácia Industrial,Universidade Federal de Santa Maria, Campus Universitário, \\ 97105-900 Santa Maria-RS, Brasil \\ ${ }^{2}$ Departamento de Farmácia Industrial, Universidade Federal de Santa Maria, Campus Universitário, \\ 97105-900 Santa Maria-RS, Brasil \\ ${ }^{3}$ Departamento de Química, Centro de Ciências Naturais e Exatas, Universidade Federal de Santa Maria, \\ Campus Universitário, 97105-900 Santa Maria-RS, Brasil
}

\begin{abstract}
RESUMO: Foram determinados parâmetros morfo-anatômicos do caule de Cuphea glutinosa cham. \& Schltdl, planta reconhecida tradicionalmente como medicinal, objetivando sua autenticidade como insumo farmacêutico. As características macroscópicas do caule são insuficientes para a determinação da autenticidade dos insumos farmacêuticos desta planta, havendo necessidade de verificar a presença de sementes não aladas e de vesículas infraestaminais nas flores. Microscopicamente a presença de formações epicuticulares, cristais de oxalato de cálcio na forma de drusas, tricomas tectores e glandulares, estômatos xerofíticos, células mucilaginosas e floema interxilemático, são características significativas no controle botânico de qualidade desta espécie para a indústria farmacêutica, quando analisadas em conjunto.
\end{abstract}

Unitermos: Cuphea glutinosa, farmacobotânica, Lythraceae, controle botânico de qualidade.

\begin{abstract}
Morpho-anatomy of the stem of Cuphea glutinosa Cham \& Schltdl. (Lythraceae)". Morpho-anatomical parameters of Cuphea glutinosa cham. \& Schltdl, stem were determined aiming its authenticity as a pharmaceutical drug. This plant is traditionally known as medicinal. The macroscopic characteristics of the stem are insuficient to determine the autenticity of this plant pharmaceutics input, it requires checking out the presence of not winged seeds and vesicles placed under the stamens of the flowers. Microscopically, the presence of epicuticular formations, crystals of calcium oxalato in druses form, glandular and non-glandular thricomes, xerophytic stomatas, mucilages cells and interxilematic phloem are meaningful characteristics in the botanical quality control of this plant for the pharmaceutical industry, when analyzed together.
\end{abstract}

Keywords: Cuphea glutinosa, pharmacobotany, Lythraceae, morpho-anatomy, botanical quality control.

\section{INTRODUÇÃO}

A família Lythraceae compreende trinta gêneros e aproximadamente quinhentas espécies. Lagerstroemia $\mathrm{L}$. é referido como o gênero mais antigo e Cuphea P. Browne como o gênero mais recente (Barroso, 1991; Reitz, 1969). Esta família apresenta distribuição pantropical e as espécies são, freqüentemente, representadas por plantas lenhosas como árvores pequenas ou de grande porte, subarbustos, arbustos e, também, por ervas anuais (Barroso, 1991; Schultz, 1985).

O gênero Cuphea é de origem centro-sul americana. Este gênero apresenta cerca de 250 espécies que ocorrem em lugares úmidos e em terrenos pedregosos.
Para a diagnose do gênero Cuphea é destacado como caracteres macroscópicos relevantes a presença de duas bractéolas, flores não opostas, folhas decussadas e estames insertos na metade superior da corola (Kissmann \& Groth, 1991; Reitz, 1969).

Santos et al. (1995) destaca para o gênero Cuphea a presença de flavonóides, sendo a maioria dos compostos flavonóides 3-O-glicosídeos e flavonas, além da ocorrência freqüente de glicosídeos e galactose. Também foi encontrado derivados de ramnetina e isoramnetina. Neste gênero, raramente ocorre derivados de kaempferol e flavonas, e é característica a ausência de ácido glicurônico e glicosídeos de miricetina. O mesmo autor afirma que a química do gênero Cuphea é bastante variável, contudo, 
o padrão geral de flavonóides das sementes, serve para o embasamento da proposta de segregação deste gênero, bem como, na diferenciação entre espécies da família Lythraceae. Chen et al. (1999) determinaram para o gênero Cuphea a presença de flavonóides, triterpenóides e ácidos graxos de cadeia curta e média, além de taninos hidrolizáveis, incluindo elagitaninos dímeros com estruturas macrocíclicas.

As partes aéreas de plantas do gênero Cuphea são utilizadas tradicionalmente pela população como estomáquica, anticancerígena, contraceptiva, antifebril, diurética, laxativa, emenagoga, no combate a sífilis, gonorréia, arterioesclerose, hipertensão arterial, hemorróidas, arritimias cardíacas e em cosméticos (Chen et al., 1999; González et al., 1994; Biavatti et al., 2007; Leitão et al., 2009). Wang et al. (1999) avaliaram a atividade antitumoral dos quatro dímeros de taninos hidrolizáveis macrocíclicos, cuphiina $\mathrm{D}_{1}$, cuphiina $\mathrm{D}_{2}$, oenotheina e woodfordina, isolados de gênero Cuphea. Todos estas quatro substâncias inibiram significativamente o crescimento de carcinoma humano de linhagem de células KB, HeLa, DU-145, Hep 3B, S-180 e de células leucêmicas HL-60, mostrando menor citotoxicidade do que a adriamicina contra células da linhagem normal (WISH). Cuphea glutinosa Cham \& Schltdl. é citada como uma espécie utilizada tradicionalmente como medicinal (González et al., 1994). Esta espécie forma, em geral, pequenas aglomerações nos campos do sul do Brasil, Bolívia, Paraguai, Uruguai e centro-leste da Argentina (Reitz, 1969).

Parâmetros morfo-anatômicos podem ser utilizados como um recurso útil no controle botânico de qualidade de um determinado órgão vegetal de valor medicinal. Este fato permite a autenticidade do material vegetal, possibilitando a diferenciação inclusive entre espécies botanicamente muito próximas (Souza et al., 2005; Di Stasi, 1996; Barbosa et al., 2007; Marques et al., 2007; Barros et al., 2008; Mauro et al., 2008; Carpano et al., 2009). Para o gênero Cuphea o estudo farmacobotânico é de fundamental importância, visto que, além do valor medicinal, Cuphea glutinosa, Cuphea carthagenensis e Cuphea ingrata, espécies conhecidas popularmente por sete-sangria, são muito similares entre si (Kissmann \& Groth, 1991; Reitz, 1969).

Este trabalho tem por objetivo a determinação de características macroscópicas e microscópicas de caules de Cuphea glutinosa Cham \& Schtdl., Lythracee, com a finalidade de contribuir para o controle botânico de qualidade desta espécie como insumo farmacêutico, uma vez que em medicina tradicional utiliza-se as partes aéreas desta planta.

\section{MATERIAL E MÉTODOS}

Os caules de Cuphea glutinosa Cham \& Schltdl. foram coletados em Santana do Livramento, RS, sendo que uma amostra do material vegetal foi identificado e depositado no Herbário do Departamento de Biologia, do Centro de Ciências Naturais e Exatas da Universidade Federal de Santa Maria, conforme exsicata SMDB 11116.

A análise morfológica foi efetuada utilizando estereomicroscópio binocular, tomando por base para a descrição macroscópica Gattuso \& Gattuso (1999) e Oliveira \& Akisue (1989). Para a análise anatômica foi utilizado seções transversais da parte mediana do caule (2 x $2 \mathrm{~mm}$ ), fixadas em glutaraldeido a 2\% em PBS e conservadas, sob refrigeração a $4{ }^{\circ} \mathrm{C}$, por $48 \mathrm{~h}$. O material foi desidratado em série etílica ascendente de 50 a $96^{\circ} \mathrm{GL}$ e incluídos em blocos de hidroxietilmetacrilato, seguindo Gerrits \& Smidt (1983). No micrótono rotativo fez-se seções de $4 \mu \mathrm{m}$, que foram levados a banho histológico, repassadas para lâmina e corados com azul de toluidina a 0,05\%, (Gerlach, 1977). Após a coloração uma lamínula foi fixada sobre as seções com bálsamo sintético. A presença de mucilagens foi detectada pela utilização de tinta da china a $0,25 \%$ e azul de metileno a $0,15 \%$ (Costa, 1982). A constituição química dos cristais foi verificada com ácido acético a $6 \%$ ou solução de ácido clorídrico a 7 \% (Costa, 1982). As seções foram analisadas tomando por base Dickison (2000), Appezzato-da-Glória \& CarmelloGuerreiro (2003), Fahn (1990) e Cutter (1987). O material foi microfotografado em microscópio com câmara digital e as lâminas depositadas no laminário do Departamento de Farmácia Industrial, Universidade Federal de Santa Maria.

\section{RESULTADOS}

\section{Análise macroscópica}

O caule exibe coloração verde-avermelhada, atinge $15-40 \mathrm{~cm}$ de comprimento e 2-4 $\mathrm{mm}$ de diâmetro. Apresenta abundante pilosidade de base avermelhada e ápice esbranquiçado. A base do caule é lenhificada e a pilosidade, nesta região, é mais esparsa. Os ramos (Figura 1) são eretos ou decumbentes e possuem diâmetro de aproximadamente $1 \mathrm{~mm}$, atingindo $2 \mathrm{~mm}$ na base, e até 10 $\mathrm{cm}$ de comprimento.
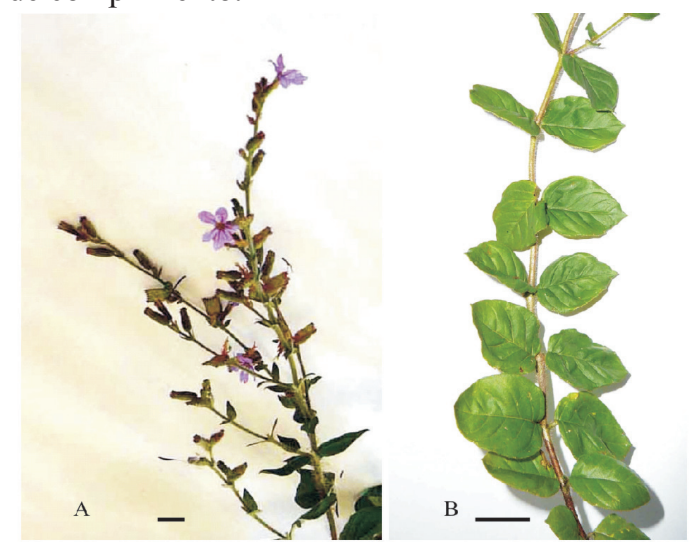

Figura 1A-B. Aspecto geral dos ramos de Cuphea glutinosa Cham. \& Schltdl. Barra $1 \mathrm{~cm}$. 


\section{Análise microscópica}

O caule de Cuphea glutinosa, no nível analisado, apresenta seção circular, epiderme uniestratificada persistente constituída de células que tendem ser ovóides e raros estômatos (Figura 2). A cutícula é plicada e persistente, exibindo formações epicuticulares lenticulares (Figura 3 A-D). É comum a presença de tricomas glandulares de pedicelo unicelular e glândula captada (Figura 3D).

Subjacente a epiderme, a região cortical constituise de células parenquimáticas, com células de tamanho e forma variada, sendo que as camadas mais externas estão constituídas de células mais achatadas, e as camadas internas de células mais circulares (Figuras 2, 3A e 3D). Os espaços intercelulares na região cortical são em geral do tipo meato (Figura 3A). Após a primeira camada de células de parênquima tem-se uma a três camadas de células mucilaginosas e, caracteristicamente, após mais uma camada de células parenquimáticas, ocorre novamente a presença de células mucilaginosas, formando pequenos grupos constituídos de 7 a 15 células (Figura 2, 3A, C e D).
O sistema vascular exibe um xilema espesso e contínuo, circundado por um floema reduzido a poucas camadas (Figuras 4A-C).

O cilindro central está formado por um maciço de tecido parenquimático, constituído por células de forma circular (Figura 2). Os espaços intercelulares são do tipo meato, porém, na região central, os espaços intercelulares são do tipo lacuna (Figura 5A). Cristais na forma de drusas podem ocorrer, de forma esporádica, nas primeiras camadas de células parenquimáticas do cilindro central (Figura 5B).

Pela análise histoquímica verificou-se que os cristais presentes, na forma de drusas, são de oxalato de cálcio, pois na presença de ácido acético a $6 \%$ são insolúveis e, na presença de ácido clorídrico a $7 \%$, os mesmos solubilizam sem produzirem efervescência. Estes cristais encontram-se nas primeiras camadas do parênquima do cilindro central do caule (Figura 5B). A presença de mucilagem foi detectada em células epidérmicas e nas formações parenquimáticas do córtex próximo a epiderme do caule (Figuras 2 e 3A, C e D).

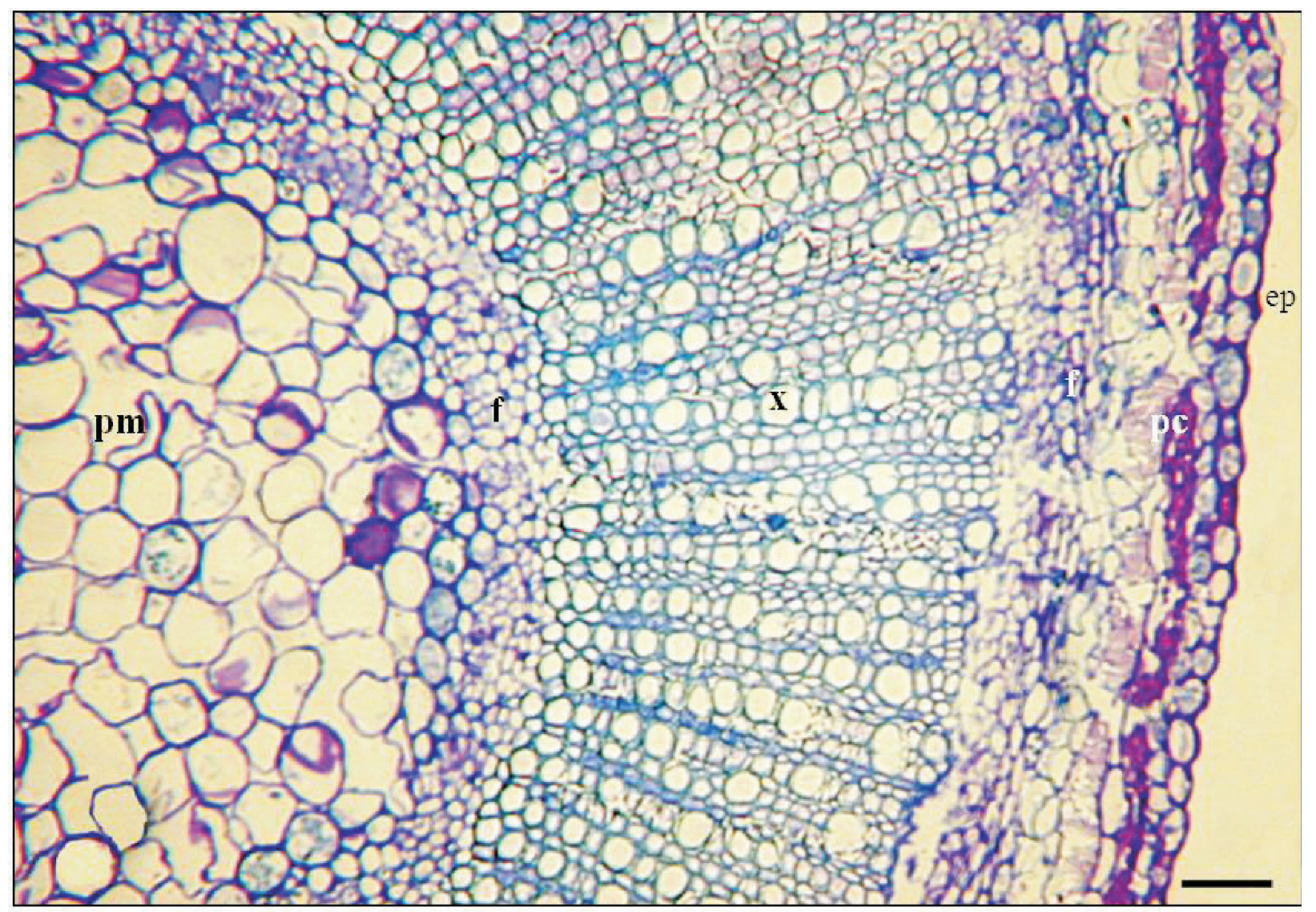

Figura 2. Aspecto geral da seção transversal do caule de Cuphea glutinosa Cham. \& Schltdl. Barra: $20 \mu$ m. Legenda: ep. epiderme; pc. parênquima cortical; f. floema; x. xilema; pm. parênquima medular. 


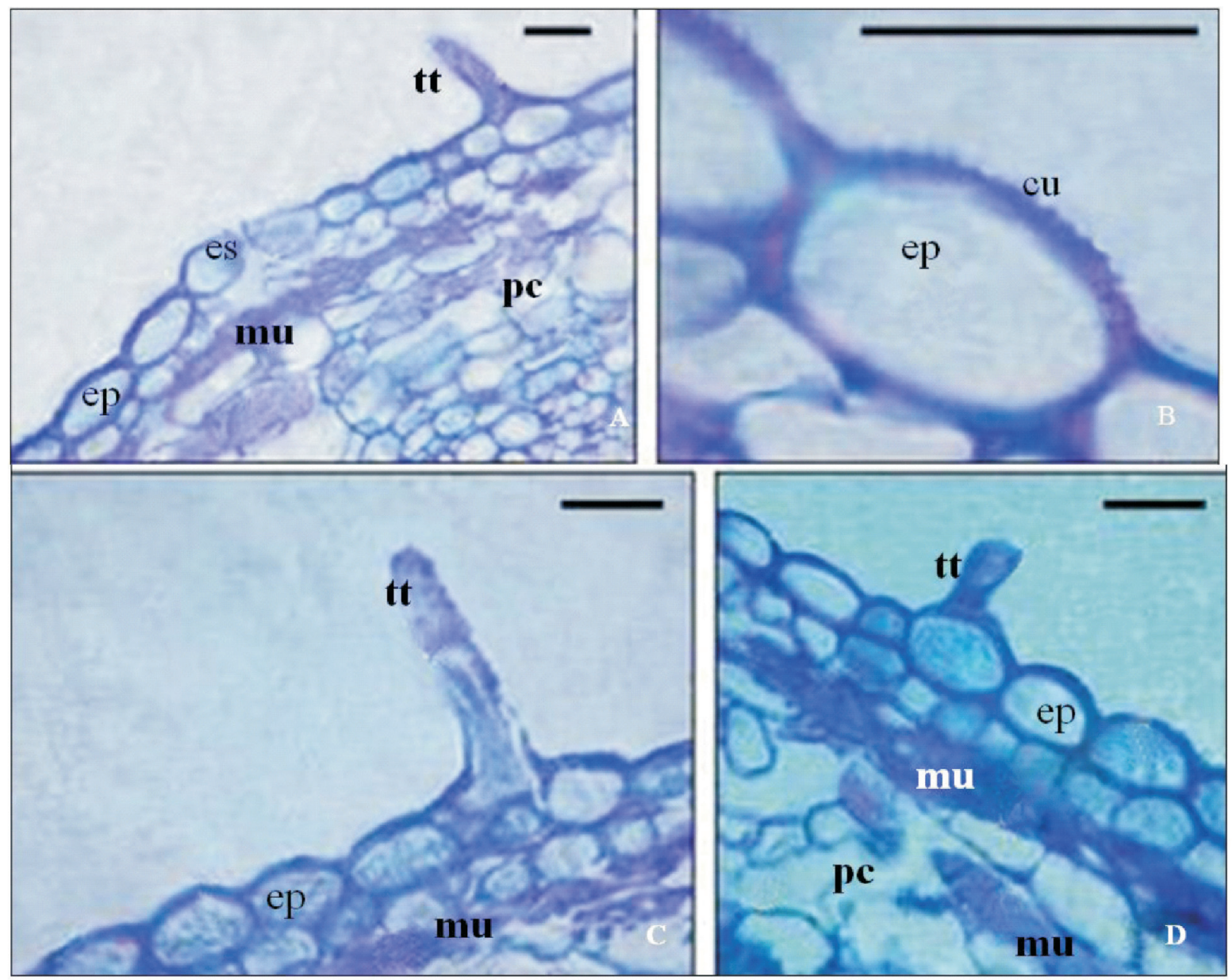

Figura 3A-D. Seção transversal do caule de Cuphea glutinosa Cham. \& Schltdl. evidenciando região epidérmica e cortical. Barra: $10 \mu \mathrm{m}$. Legenda: cu. cutícula com formações lenticulares ep. células epidérmicas; es. estômato; tt. Tricoma tector; pc. parênquima cortical; mu. células de mucilagem.
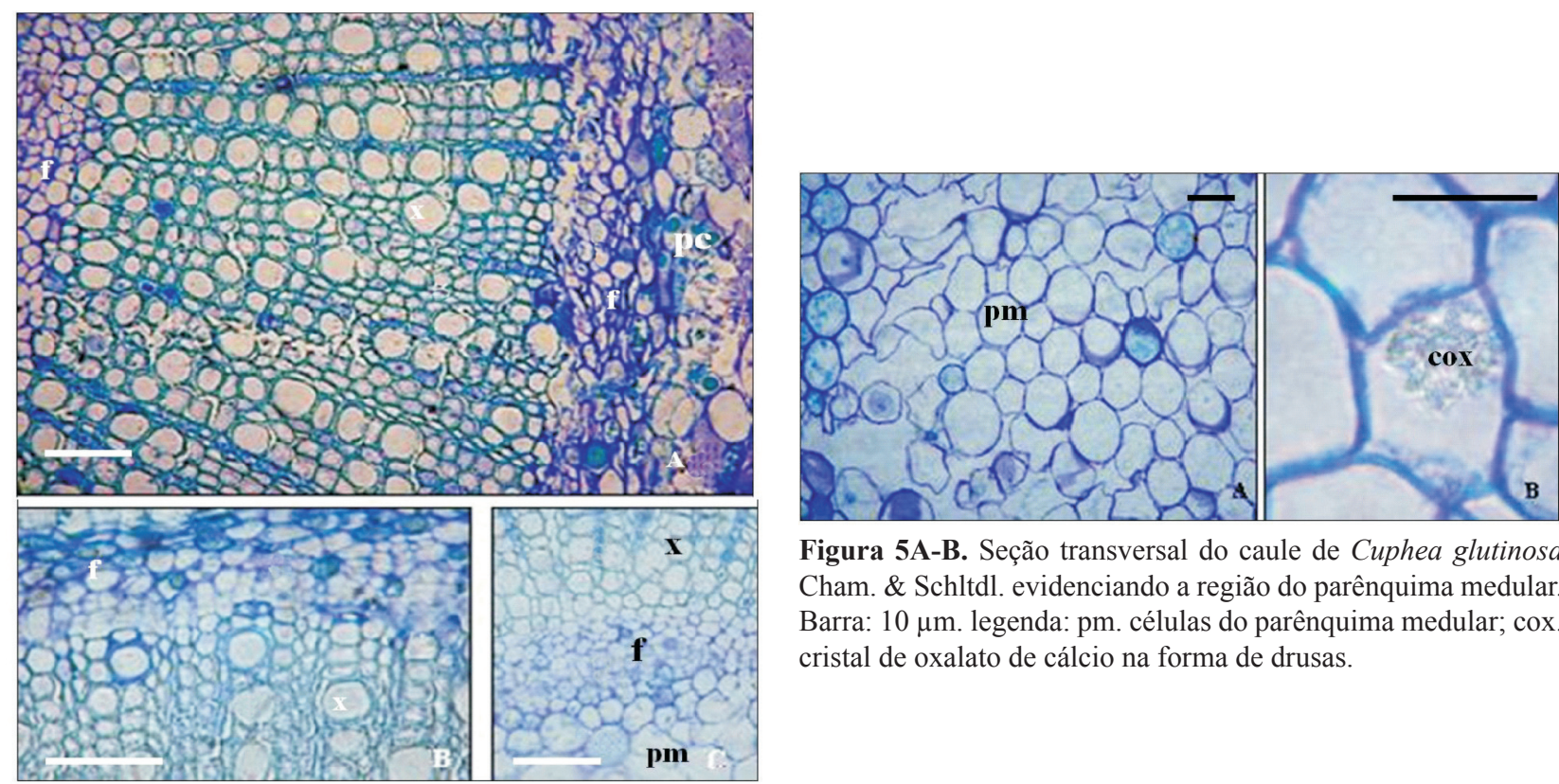

Figura 5A-B. Seção transversal do caule de Cuphea glutinosa Cham. \& Schltdl. evidenciando a região do parênquima medular. Barra: $10 \mu \mathrm{m}$. legenda: pm. células do parênquima medular; cox. cristal de oxalato de cálcio na forma de drusas.

Figura 4A-C. Seção transversal do caule de Cuphea glutinosa Cham. \& Schltdl. evidenciando o sistema vascular. Barra: $20 \mu \mathrm{m}$. Legenda: f. floema; x. xilema; pc. células do parênquima cortical; pm. células do Parênquima medular. 


\section{DISCUSSÃO}

A análise macro e microscópica dos mais diferentes órgãos de uma planta, os detalhes e as variações que ocorrem nos tecidos vegetais contribuem para a diferenciação correta entre espécies e consequentemente no controle de qualidade de drogas vegetais. Em relação a análise macroscópica do caule de Cuphea glutinosa foi verificado que os caracteres morfológicos coincidem com os descritos para a família Lythraceae por Joly (1998), Barroso (1991) e Schultz (1985) como a base lenhificada do caule, foi observada neste trbalho e é concordante com as descrições de Reitz (1969) e Kissmann \& Groth (1991) para a espécie em questão. Contudo, devido a plasticidade fenotípica do órgão estudado e a similaridade que o mesmo apresenta com os de outras espécies do mesmo gênero, em particular de Cuphea ingrata e Cuphea carthagenensis, é pertinente que na determinação da autenticidade de Cuphea glutinosa seja considerado caracteres em outros órgãos que não somente caules.

Em alguns insumos farmacêuticos há a necessidade da observação de caracteres macroscópicos que não apenas aqueles no órgão em questão, o que se deve pela similaridade morfológica entre algumas espécies vegetais. Este é o caso de Achirocline satureioides, que apesar das inflorescências desta espécie serem utilizadas como medicinais, a Farmacopéia Brasileira (1988), recomenda a verificação da presença de caules alados no material vegetal. Por outro lado, quando as características macroscópicas dos insumos farmacêuticos são pouco consistentes, os caracteres microscópicos tomam maior destaque na averiguação da autenticidade dos mesmos. Para Cuphea glutinosa, dentre os caracteres macroscópicos, conforme Reitz (1969), destaca-se as pétalas violáceas sem a presença de vesículas infra-estaminais, uma vez que estas vesículas ocorrem em Cuphea ingrata. Outro caracter importante a ser observado está nas sementes, pois em Cuphea glutinosa as sementes não são aladas como em Cuphea carthagenensis. Além destes caracteres, úteis na determinação da autenticidade de Cuphea glutinosa, somase a presença de 10 a 15 (até 20) óvulos e o tamanho das sementes, de aproximadamente $2 \mathrm{~mm}$, para esta espécie vegetal. Devido ao tamanho diminuto dos diversos órgãos de Cuphea glutinosa, os insumos farmacêuticos desta planta, constituem-se das partes aéreas como um todo. Assim é que tanto os caracteres florais como os caracteres encontrados nas sementes de Cuphea glutinosa, citados neste trabalho, podem ser observados inclusive em seus insumos rasurados ou pulverizados.

A presença de floema interxilemático e de células mucilaginosas, constatadas em Cuphea glutinosa por análise microscópica neste trabalho, são características anatômicas concordantes para a família Lythraceae conforme Metcalfe \& Chalk (1950). Assim é que, as variações e particularidades que ocorrem nestas características constituem-se como marcadores anatômicos importantes na determinação de gêneros ou de espécies desta família vegetal.

Em Cuphea glutinosa, fica evidente a ocorrência de formações lenticulares por toda a extensão da cutícula que recobre as células epiteliais do caule. Autores como Dickison (2000) e Oliveira et al. (1993) destacam que as características da cutícula e das formações epicuticulares são marcadores anatômicos relevantes na diferença entre espécies vegetais. Neste sentido, Garcia et al. (2004), por exemplo, observaram diferenças na espessura e forma entre as cutículas de Phyllanthus niruri e Phyllanthus tenellus, espécies botanicamente muito similares.

Uma característica microscópica marcante em Cuphea glutinosa constitui-se na presença de tricomas, o que pode ser constatado em toda a extensão da epiderme do caule. Oliveira et al. (1993), destacam que os tricomas são características de grande valia na diagnose da droga vegetal, principalmente quando este se apresenta fragmentado ou mesmo pulverizado. Metcalfe \& Chalk (1988) relatam que a freqüência e o tamanho dos tricomas podem variar em razão das condições ambientais, de maneira que a classificação do tipo de tricomas é mais consistente para a autenticidade de drogas vegetais.

Em geral os tricomas são discutidos como anexos epidérmicos capazes de reduzirem a transpiração ao produzirem uma camada de ar parado que retém vapor (Fahn, 1986; Ricklefs, 1993), além do que, conforme Holmes \& Keiller (2002) e Hallahan et al. (2000) os órgãos pubescentes tendem a ser mais efetivos na reflexão da radiação solar. Estas considerações vêm ao encontro da ocupação natural de Cuphea glutinosa em locais de campo aberto, ambiente que exige certa proteção em relação a transpiração excessiva e também na reflexão da radiação luminosa intensa. Por outro lado, estas estruturas epidérmicas, conforme Hallahan et al. (2000) e Gurevitch et al. (2002) também estão associadas ao papel de defesa das plantas à ação de herbívoros e fitopatógenos, pois podem dificultar o sucesso de processos como os de pouso e oviposição. Gruenhagen \& Perring (2001), afirmam que além da quantidade, mas a presença e a natureza de tricomas nas plantas podem estar diretamente relacionadas com as taxas de parasitismos.

Em Cuphea glutinosa é constante a presença de cristais de oxalato de cálcio na forma de drusas. Os cristais, nas suas mais variadas formas e constituição química, revelam-se como uma característica importante na autenticidade de drogas vegetais. Além da presença ou ausência de cristais, a forma e a localização topográfica destas estruturas constituem-se como características importantes em farmacobotânica. Genua \& Hillson (1985), por exemplo, destacam para o gênero Dieffenbachia, a presença de drusas e a ausência de ráfides na epiderme foliar de Dieffenbachia picta, diferem-na de Dieffenbachia maculata, pois esta última apresenta drusas no mesofilo e ráfides no mesofilo e na epiderme foliar. Em Cuphea glutinosa foi observado apenas cristais de oxalato de 
cálcio e somente na forma de drusas, características que podem ser consideradas como relevantes na autenticidade dos insumos farmacêuticos desta espécie vegetal.

Inúmeras funções têm sido atribuídas para justificar a presença dos cristais de oxalato de cálcio nos mais diversos órgãos vegetais. Nakata (2003) destaca como funções relacionadas a estes cristais a defesa à herbivoria, a concentração e difusão luminosa, a regulação metabólica de cálcio, bem como a detoxificação de ácido oxálico ou de metais pesados e a sustentação dos mais variados tecidos vegetais. Trachtenberg \& Mayer (1981) sugerem uma relação funcional entre as células mucilaginosas e os cristais de oxalato de cálcio. Os cristais teriam papel fundamental no suprimento de cálcio, que seria transferido para as células mucilaginosas, ligando-se às pectinas e auxiliando, em última análise, no armazenamento de água. Novamente tem-se com estas referências mais uma justificativa que poderia explicar à ocupação natural de Cuphea glutinosa em ambientes de campo aberto, alén do que é freqüente a presença de células mucilaginosas nesta espécie vegetal.

Sajo \& Rudall (2002) e Metcalfe \& Chalk (1950) destacam que as células mucilaginosas constituem-se em uma característica xeromórfica, atuando basicamente na manutenção de água para os diversos órgãos vegetais. A presença marcante de células mucilaginosas em seções do caule é uma característica a ser destacada para Cuphea glutinosa. Conforme O'Brien \& McCully (1981), o azul de toluidina cora de púrpura (lilás) as substâncias pécticas que constituem as mucilagens. Assim é que com a utilização deste reagente detecta-se, por coloração, prontamente as células de mucilagem. A presença destas células mucilaginosas foi confirmada pela utilização de tinta da china ou azul de metileno em seções de material fresco de Cuphea glutinosa.

Sajo \& Rudall (2002) e Bakker \& Gerritsen (1992) ressaltam que as células mucilaginosas podem ter valor taxonômico. Costa (1982) afirma que dentre os diferentes grupos taxonômicos a localização histológica de compostos mucilaginosos é constante, característica que torna-se importante na identificação de inúmeras espécies vegetais e, consequentemente, na autenticidade de um determinado material botânico.

\section{REFERÊNCIAS}

Appezzato-da-Glória B, Carmello-Guerreiro SM 2003. Anatomia vegetal. Viçosa: Editora UFV.

Bakker ME, Gerritsen AF 1992. Oil and mucilage cells in Annona (Annonaceae) and their systematic significance. Blumea 36: 411-438.

Barbosa DA, Silva KN, Agra MF 2007. Estudo farmacobotânico comparativo de folhas de Turnera chamaedrifolia Cambess. e Turnera subulata Sm. (Turneraceae). Rev Bras Farmacogn 17: 396-413.

Barros GMSC, Teixeira SP 2008. Estudo farmacobotânico de duas espécies de Anileira (Indigofera suffruticosa e Indigofera truxillensis, Leguminosae) com propriedades farmacológicas. Rev Bras Farmacogn 18: 287-294.

Barroso GM 1991. Sistemática de Angiospermas do Brasil. Vol. 2. Viçossa: Universitária, 377 p.

Biavatti M, Marensi V, Leite SN, Reis A 2007. Ethnopharmacognostic survey on botanical compendia for potential cosmeceutic species from Atlantic Forest. Rev Bras Farmacogn 17: 640-653.

Carpano SM, Castro MT, Spegazzini ED 2009. Caracterización morfoanatómica comparativa entre Aloe vera (L.) Burm. F., Aloe arborescens Mill., Aloe saponaria Haw. y Aloe ciliaris Haw. (Aloeaceae). Rev Bras Farmacogn 19: 269275.

Chen GL, Yen YK, Yang, LL, Hatano T, Okuda T, Yoshida T 1999. Macrocyclic ellagitannin dimers, cuphiins $\mathrm{D}_{1}$ and $\mathrm{D}_{2}$, and accompanying tannins from Cuphea hyssopifolia. Phytochemistry 50: 307-312.

Costa AF 1982. Farmacognosia. Vol. III 2 ed. Lisboa: Fundação Calouste Gulbenkian.

Cutter EG 1987. Anatomia vegetal. Parte II Órgãos. Experimentos e interpretações. São Paulo: Rocca.

Di Stasi LC 1996. Plantas medicinais: Arte e ciência. São Paulo: UNESP.

Dickison WC 2000. Integrative plant anatomy. San Diego: Academic Press.

Fahn A 1986. Strctural and functional properties of trichomes of xeromorphyc leaves. Ann Bot 57: 631-63

Fahn A 1990. Plant anatomy. Oxford: Pergamon Press.

Farmacopéia Brasileira 1988. 4 ed. São Paulo: Atheneu.

Garcia CM, Zanetti GD, Zago AM, Bittencourt CF, Heinzmann BM 2004. Estudo morfo-anatômico de Phyllanthus niruri L. e Phyllanthus tenellus Roxb. Acta Farm Bonaerense 23: 67-70.

Gattuso MA, Gattuso SJ 1999. Manual de procedimentos para analisis de drogas em polvo. Rosário: Editora da Universidade Nacional de Rosário.

Genua JM, Hillson CJ 1985. The occurrence, type and location of calcium oxalate crystals in the leaves of fourteen species of Araceae. Ann Bot 56: 351-361.

Gerlach D 1977. Bothanische mikrotechnik. 2 ed. Stuttgard: Georg-Thieme Verlag.

Gerrits PO, Smidt L 1983. New less toxic polimerization system for the embedding of soft tissue in glycolmethacrylate and subsequent preparing of serial section. $J$ Microbiol 132: 81-85.

González AG, Valencia E, Bermejo Barrera J, Grupta MP 1994. Chemical components of Cuphea species. Carthagenol: A new triterpene from C. carthagenensis. Planta Med 60: 592-593.

Gruenhegen NM, Perring TM 2001. Impact of leaf trichomes on parasitoid behavior and parasitism of silverleaf whiteflies (Homptera: Aleyrodidae). Southwest Entomol. 26: 279290.

Gurevitch J, Scheiner SM, Fox GA 2002. The ecology of plants. Sinauer Associates Inc. Sunderland: Massachusetts. 
Hallahan DL, Gray JC, Callow JA 2000. Advances in botanical research: incorporating Advances in Plant Pathology - Plant Trichomes. San Diego, California: Academic Press.

Holmes MG, Keiller DR 2002. Effects of pubescence and waxes on the reflectance of leaves in the ultraviolet and photosynthetic wavebands: a comparison of a range of species. Plant Cell Environ 25: 85-93.

Joly AB 1998. Botânica: Introdução à taxonomia vegetal. 12 ed. São Paulo: Nacional.

Kissmann KG, Groth D 1991. Plantas infestantes e nocivas. Vol. III. São Paulo: BASF.

Leitão F, Fonseca-Kruel VS, Silva IM, Reinert F 2009. Urban ethnobotany in Petrópolis and Nova Friburgo (Rio de Janeiro, Brazil). Rev Bras Farmacogn 19: 333-342.

Marques LC, Pieri C, Roman-Júnior WA, Cardoso MLC, Milaneze-Gutierre MA, Mello JCP 2007. Controle farmacognóstico das raízes de Heteropteris aphrodisiaca O. Mach. (Malpighiaceae). Rev Bras Farmacogn 17: 604-615.

Mauro C, Silva CP, Missima J, Ohnuki T, Rinaldi RB, Frota M 2008. Estudo anatômico comparado de órgãos vegetativos de boldo miúdo, Plectranthus ornatus Codd. e malvariço, Plectranthus amboinicus (Lour.) Spreng. - Lamiaceae. Rev Bras Farmacogn 18: 608-613.

Metcalfe CR, Chalk L 1950. Anatomy of the dicotyledons. Vol I Oxford: Claredon Press.

Metcalfe CR, Chalk L 1988. Anatomy of the dicotyledons. Vol I 2 ed. Oxford: Claredon Press.

Nakata PA 2003. Advances in our understanding of calcium oxalate crystal formation and function in plants. Plant Sci 164: 901-909.

O' Brien TP, Mc Cully ME 1981. The study of plant structure principles and selected methods. Melbourne: Termocarphipty.

Oliveira F, Akisue G 1989. Fundamentos de farmacobotânica. São Paulo: Atheneu.

Oliveira F, Akisue G 1991. Farmacobotânica. São Paulo: Atheneu.

Oliveira F, Lúcia M, Garcia LO 1993. Caracterização farmacognóstica da droga e do extrato fluído de mentrasto Ageratum conyzoides L. Lecta 11: 63-100.

Reitz R 1969. Flora Ilustrada Catarinense. Litraceae. Itajaí: Publicação Herbário Barbosa Rodrigues.

Rickefs RE 1993. A economia da natureza. Rio de janeiro: Guanabara Koogan.

Sajo MG, Rudall PJ 2002. Leaf and stem anatomy of Vochysiaceae in relation to subfamilial systematics. Bot J Linn Soc 138: 339-364.

Santos DYAC, Salatino MLF, Salatio A 1995. Flavonoids of species of Cuphea (Lythraceae) from Brazil. Biochem Syst Ecol 23: 99-103.

Schultz A 1985. Introdução à botânica sistemática. Vol II.5 ed. Porto Alegre: UFRGS.

Souza TJT, Manfron MP, Zanetti GD, Hoelzel SCSM, Pagliarini VP 2005. Análise morfo-histológica e fitoquímica de
Vebena litoralis Kunt. Acta Farm Bonaerense 24: 209214.

Trachtenberg S, Mayer AM 1981. Calcium oxalate crystal in Opuntia ficus-indica: development and relation to mucilage cells A stereologicalanalysis. Protoplasma 109: 271-283.

Wang CC, Chen LG, Yang LL 1999. Antitumor activity of four macrocyclic ellagitannins from Cuphea hyssopifolia. Cancer Lett 140: 195-200. 